\title{
Thermal Conductivity of High Performance Concrete in Wide Temperature and Moisture Ranges
}

\author{
J. Toman, R. Černý
}

The thermal conductivity of two types of high performance concrete was measured in the temperature range from $100^{\circ} \mathrm{C}$ to $800^{\circ} \mathrm{C}$ and in the moisture range from dry material to saturation water content. A transient measuring method based on analysis of the measured temperature fields was chosen for the high temperature measurements, and a commercial hot wire device was employed in room temperature measurements of the effect of moisture on thermal conductivity. The measured results reveal that both temperature and moisture exhibit significant effects on the values of thermal conductivity, and these effects are quite comparable from the point of view of the magnitude of the observed variations.

Keywords: concrete, thermal conductivity, moisture content, temperature.

\section{Introduction}

Thermal conductivity $K$ of porous materials is generally a function of a number of external environmental parameters, the most important of them being temperature $T$ and moisture $u$. In usual performance conditions, when relatively narrow temperature and moisture ranges occur, the dependence of $K$ on $T$ and $u$ can be neglected. However, in certain circumstances particularly the dependence of $K$ on $T$ may appear to be very relevant. A typical example is the behavior of a building structure during a fire (see [1]).

Employing classical methods for measuring the thermal conductivity of porous materials at high temperatures may lead to certain difficulties due to the necessity of using largescale specimens and high-temperature resisting probes. In addition, most of these methods (e.g., [2-5]) enable only measurements of constant thermal conductivity, which makes the determination of the $K(T)$ relation very time consuming and leads to a loss of precision due to the necessary averaging over some temperature range.

A good alternative to classical treatments is to solve an inverse problem of heat conduction and to determine the temperature dependence of thermal conductivity from the temperature field. In this paper, an integral method using a doubleintegration treatment for solving the inverse problem of heat conduction in porous materials is employed. This method has been shown to deal with the problems of numerical instability and lack of universality known in the commonly used differential methods [6].

\section{Measuring methods}

For high temperature measurements of thermal conductivity, we employed a double integration method developed earlier by our group [6]. We will show the main features of the derivation of the method, for the convenience of the reader. We have the one-dimensional heat conduction equation in the form

$$
\rho c \frac{\partial T}{\partial t}=\frac{\partial}{\partial x}\left(K \frac{\partial T}{\partial x}\right)
$$

where $K$ is the thermal conductivity, $\rho$ the density and $c$ the specific heat.
We suppose $T(t)$ and $T(x)$ to be monotonous functions and choose a constant value of temperature, $\tau=T(x, t)$. There must exist one-to-one parametrizations $x=x_{0}(\tau, t), t=t_{0}(\tau, x)$ where both $x_{0}$ and $t_{0}$ are monotonous functions. Considering this fact, integration of heat conduction equation (1) by $x$ and $t$ leads to

$$
\begin{aligned}
& \int_{t_{1}}^{t_{2}} \int_{0}^{x_{0}(\tau, t)} \rho c \frac{\partial \mathrm{T}}{\partial t}(x, t) \mathrm{d} x \mathrm{~d} t= \\
& =K(\tau) \int_{t_{1}}^{t_{2}} \frac{\partial T}{\partial x}\left(x_{0}(\tau, t), t\right) \mathrm{d} t+\int_{t_{1}}^{t_{2}} j_{q}(0, t) \mathrm{d} t,
\end{aligned}
$$

where the heat flux at $x=0, j_{q}(0, t)$, reads

$$
j_{q}(0, t)=-K(T) \frac{\partial T}{\partial x}(0, t) .
$$

The left-hand side of equation (2) can be modified by accounting for the shape of the integration area:

$$
L S=\int_{t_{1}}^{t_{2}} \int_{0}^{x_{0}(\tau, t)} \rho c \frac{\partial T}{\partial t}(x, t) \mathrm{d} x \mathrm{~d} t=
$$

$$
=\int_{0}^{x_{0}\left(\tau, t_{1}\right)} \int_{t_{1}}^{t_{2}} \rho c \frac{\partial T}{\partial t}(x, t) \mathrm{d} x \mathrm{~d} t=\int_{x_{0}\left(\tau, t_{1}\right)}^{x_{0}\left(\tau, t_{2}\right)} \int_{t_{0}(\tau, x)}^{t_{2}} \rho c \frac{\partial T}{\partial t}(x, t) \mathrm{d} x \mathrm{~d} t .
$$

Denoting $I T=\int \rho c \frac{\partial T}{\partial t} \mathrm{~d} t=\int \rho(\mathrm{T}) c(\mathrm{~T}) \mathrm{d} T$ we obtain

$$
\begin{gathered}
L S=\int_{0}^{x_{0}\left(\tau, t_{1}\right)}\left(I_{T}\left(T\left(x, t_{2}\right)\right)-I_{T}\left(T\left(x, t_{1}\right)\right)\right) \mathrm{d} x+ \\
+\int_{x_{0}\left(\tau, t_{1}\right)}^{x_{0}\left(\tau, t_{2}\right)}\left(I_{T}\left(T\left(x, t_{2}\right)\right)-I_{T}(\tau)\right) \mathrm{d} x= \\
=\int_{0}^{x_{0}\left(\tau, t_{2}\right)} I_{T}\left(T\left(x, t_{2}\right)\right) \mathrm{d} x-\int_{0}^{x_{0}\left(\tau, t_{1}\right)} I_{T}\left(T\left(x, t_{1}\right)\right) \mathrm{d} x+ \\
-I_{T}(\tau)\left[x_{0}\left(\tau, t_{2}\right)-x_{0}\left(\tau, t_{1}\right)\right] .
\end{gathered}
$$

Substituting (5) into (2) we obtain 


$$
\begin{aligned}
K(\tau) & =\frac{1}{\int_{t_{1}}^{t_{2}} \frac{\partial T}{\partial x}\left(x_{0}(\tau, t), t\right) \mathrm{d} t}\left(\int_{0}^{x_{0}\left(\tau, t_{2}\right)} I_{T}\left(T\left(x, t_{2}\right)\right) \mathrm{d} x+\right. \\
-\int_{0}^{x_{0}\left(\tau, t_{1}\right)} I_{T}\left(T\left(x, t_{1}\right)\right) \mathrm{d} x-I_{T}(\tau)\left[x_{0}\left(\tau, t_{2}\right)-x_{0}\left(\tau, t_{1}\right)\right]+ & \left.-\int_{t_{1}}^{t_{2}} j_{q}(0, t) \mathrm{d} t\right) .
\end{aligned}
$$

In Eq. (6), some difficulties may arise in determining the heat flux $j_{q}(0, t)$. Basically, we have two ways how to deal with this problem: either to measure $j_{q}(0, t)$ directly or to calculate it from the known temperature field $T(x, t)$. In the high temperature range that we are interested in, measuring $j_{q}(0, t)$ is relatively difficult. Therefore, we choose the numerical treatment, and supposing that in the initial state the boundary condition for temperature on the opposite side of the one-sided heated sample is not yet influencing the temperature field, we calculate $j_{q}(0, t)$ from the formula

$j_{q}(0, t)=\frac{1}{t_{2}-t_{1}} \int_{0}^{l}\left[\rho(T) c(T) T\left(x, t_{2}\right)-\rho(T) c(T) T\left(x, t_{1}\right)\right] \mathrm{d} x,(7)$

where $l$ is the length of the one-dimensional sample.

For the room temperature measurements, we employed the Shotherm QTM (Showa Denko) commercial hot wire device.

\section{Materials and samples}

The experimental work was done with two types of high performance concrete used in nuclear power plants: Penly concrete and Temelin concrete.

Penly concrete was used for a concrete containment building in a nuclear power plant in France (samples were obtained from M. Dugat, Bouygues Company, France). It had a dry density of $2290 \mathrm{~kg} / \mathrm{m}^{3}$, and consisted of the following components: Cement CPA HP Le Havre $\left(290 \mathrm{kgm}^{-3}\right)$, sand $0 / 5$ size fraction $\left(831 \mathrm{kgm}^{-3}\right)$, gravel sand $5 / 12.5$ size fraction $\left(287 \mathrm{kgm}^{-3}\right)$, gravel sand $12.5 / 25$ size fraction $\left(752 \mathrm{kgm}^{-3}\right)$, calcareous filler PIKETTY $\left(105 \mathrm{kgm}^{-3}\right)$, silica fume $\left(30 \mathrm{kgm}^{-3}\right)$, water $\left(131 \mathrm{kgm}^{-3}\right)$, retarder CHRYTARD 1.7 , super-plasticizer Resine GT 10.62. The maximum water saturation was $4 \% \mathrm{~kg} / \mathrm{kg}$.

The Temelin concrete used for the concrete containment building of the Temelin nuclear power plant in the Czech Republic had a dry density of $2200 \mathrm{~kg} / \mathrm{m}^{3}$ and maximum water saturation $7 \% \mathrm{~kg} / \mathrm{kg}$. The composition was as follows: Cement 42.5 R Mokrá $\left(499 \mathrm{kgm}^{-3}\right)$, sand 0/4 size fraction $\left(705 \mathrm{kgm}^{-3}\right)$, gravel sand $8 / 16$ size fraction $\left(460 \mathrm{kgm}^{-3}\right)$, gravel sand $16 / 22$ size fraction $\left(527 \mathrm{kgm}^{-3}\right)$, water $\left(215 \mathrm{kgm}^{-3}\right)$, plasticizer $4.5 \mathrm{~lm}^{-3}$.

For high temperature measurements of thermal conductivity, we used cubic specimens $71 \times 71 \times 71 \mathrm{~mm}$, and for room temperature measurements prismatic specimens $40 \times 40 \times 160 \mathrm{~mm}$.

\section{Experimental results}

\subsection{Temperature dependence of thermal conductivity}

The high temperature measurements of thermal conductivity are summarized in Figs. 1a, b. The two materials

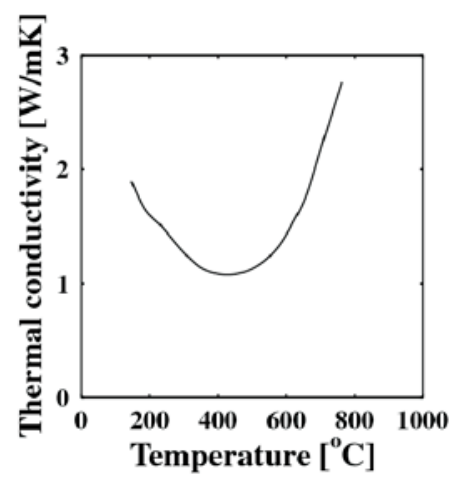

Fig. 1a: Dependence of the thermal conductivity of Temelin concrete on temperature

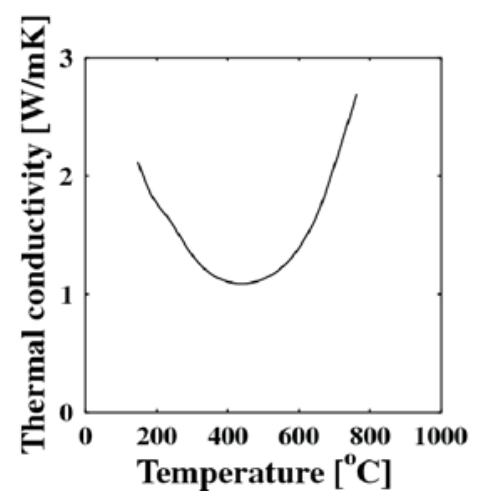

Fig. 1b: Dependence of the thermal conductivity of Penly concrete on temperature

exhibited very similar behavior. In the temperature range to $400{ }^{\circ} \mathrm{C}$, we observed a characteristic decrease of thermal conductivity which is well known for instance for monocrystalline metals or semiconductors. For temperatures above $400{ }^{\circ} \mathrm{C}$, the thermal conductivity began to increase, which is an unexpected feature. This unusual behavior of both materials can be explained by structural changes in this temperature range, which are mainly due to the loss of crystallically bonded water and dehydration of some components.

\subsection{Moisture dependence of thermal conductivity}

The measured results are shown in Figs. 2a, b where the different markers denote different samples. The measured

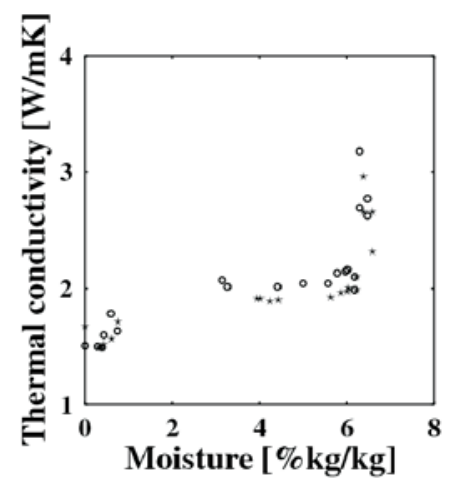

Fig. 2a: Dependence of the thermal conductivity of Temelin concrete on the moisture content 


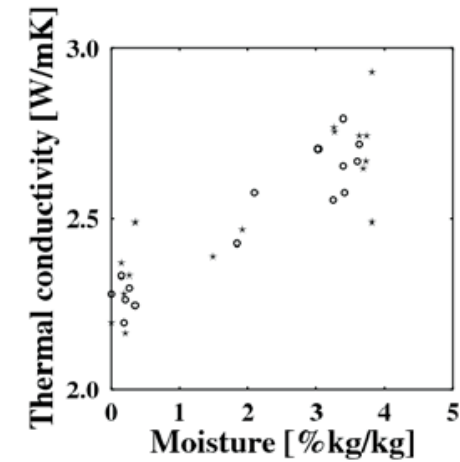

Fig. 2b: Dependence of the thermal conductivity of Penly concrete on the moisture content

results exhibit significant changes in thermal conductivity due to the moisture variations which are quite comparable to those due to high temperature exposure. The data for high values of moisture, close to the saturation moisture content, are split, which might be a consequence of structural damage caused by the water saturation process.

\section{Conclusions}

The thermal conductivity of the two types of high performance concrete was determined in wide temperature and moisture ranges. Both temperature and moisture effects were found to be very important. They could result in variations of thermal conductivity as high as 50 or more per cent compared to the reference values.

\section{Acknowledgement}

This paper is based on work supported by the Ministry of Education of the Czech Republic, under contract No. CEZ:J04/98:210000003.

\section{References}

[1] Toman, J.: Influence of External Conditions on Building Materials and Constructions. Thesis, CTU Prague 1986

[2] Dickerson, Jr., R. W.: Food Technol., 19, 198 (1965)

[3] Rao, M. A., Barnard, J. and Kenny, J. F.: Trans. ASAE, 16, 1143 (1975)

[4] Dreyer, J. and Rogass, H.: Proc. of the 4. Bauklimatisches Symp., Dresden 1982, p. 53

[5] Venzmer, H. and Černý, R.: Stavebnícky časopis, 38, 105 (1990) (in Czech)

[6] Černý, R., Toman, J.: Proc. of International Symposium on Moisture Problems in Building Walls, V.P. de Freitas, V. Abrantes (eds.), p. 299, Univ. of Porto, 1995

Prof. Mgr. Jan Toman, DrSc.

Department of Physics

phone: +420224354694

e-mail:toman@fsv.cvut.cz

Prof. Ing. Robert Černý, DrSc.

Department of Structural Mechanics

phone: +420224354429

e-mail: cernyr@fsv.cvut.cz

CTU, Faculty of Civil Engineering

Thákurova 7, 16629 Prague 6

Czech Republic 